\title{
The Methodology for Strategic Plan Implementation
}

\author{
J. Rojas-Arce ${ }^{\star^{1}}$, O. Gelman ${ }^{2}$, J. Suárez-Rocha ${ }^{3}$ \\ ${ }^{1,3}$ Departamento de Ingeniería de Sistemas, Posgrado de Ingeniería, \\ Universidad Nacional Autónoma de México, \\ Circuito Escolar s/n, Ciudad Universitaria, \\ Coyoacán, CP 04510, Mexico City, Mexico, CP 04510 \\ *jorge_rojas_79@yahoo.com.mx \\ ${ }^{2}$ Grupo de Sistemas de Soporte Informático en Organizaciones, \\ Departamento de Tecnologías de la Información, \\ Centro de Ciencias Aplicadas y Desarrollo Tecnológico, \\ Universidad Nacional Autónoma de México \\ Circuito Exterior, Ciudad Universitaria, Coyoacán, CP 04510, México City, D.F.
}

\begin{abstract}
The objective of this paper is to propose the methodology for the implementation of strategic plans in organizations through the prevention and, in its case, the definition and solution of the problems that frequently affect the implementation processes with many negative manifestations and harmful consequences. By elaborating the concept of implementation under the systems approach and cybernetic paradigm, two types of these problems have been identified: the organizational and the functional ones. The consequent analysis of each kind of them has permitted the development of a methodology for their prevention, identification and solution to assure an effective and efficient implementation process. This methodology consists in realizing five subsequent procedures, which were validated with positive results obtained through their virtual application to the different cases of manifestations with the negative consequences that had occurred during strategic plans implementations described in literature.
\end{abstract}

Keywords: Implementation of strategic plans, systems approach, cybernetic paradigm, planning process, management process.

\section{RESUMEN}

El objetivo de este artículo es proponer la metodología para la implementación de planes estratégicos en organizaciones, a través de la prevención y, en su caso, de la definición y solución de los problemas que afectan frecuentemente los procesos de implementación con muchas manifestaciones y nocivas consecuencias. Dos tipos de estos problemas, organizacionales y funcionales, han sido identificados a través de la elaboración del concepto de implementación bajo el enfoque sistémico y paradigma cibernético. El consecuente análisis de cada uno de ellos ha permitido desarrollar una metodología para su prevención, identificación y solución con el fin de asegurar el eficaz y eficiente proceso de la implementación. Esta metodología consiste en la realización de cinco procedimientos consecuenciales que fueron validados con resultados positivos obtenidos a través de su aplicación virtual a los diferentes casos de manifestaciones con sus consecuencias negativas ocurridas durante implementaciones de planes estratégicos descritos en la bibliografía.

\section{Introduction}

The implementation of a strategic plan consists in carrying out one or more strategies established in the plan [1]. Depending on the purposes of the plan and time horizons, a strategic plan is implemented through the realization of tactical and operational plans $[2,3]$, which include programs, projects and actions sequences.

But frequently during the implementation process, certain (sometimes, very serious) problems occur that do not permit to obtain the planned results in projected time, resulting as well in overrunning of the assigned resources and/or what is worst, in spite of all efforts and expenses, in not achieving the planed objectives.

Usually the problems are not presented directly, but their existence could be observed through the manifestations and the negative consequences which they cause. The literature is full of 
descriptions of these manifestations and cases in which the strategic plan does not contain the specific activities that are indispensable for its implementation [4], or in which the coordination of these activities is not effective enough to achieve the planned results [4,5]. Moreover, there are described cases in which, during the plan implementation, there is the need to improvise actions [6], because these actions had not been foreseen and, besides, the necessity of their execution had not been defined and/or scheduled. According to the authors' opinions, that occurs when the plan is conceived as a purely political instrument or when its execution is considered as a post-strategic process with other requirements [7, 8]. In other cases, some difficulties are presented in making adjustments during the implementation due to insufficient flexibility of the plan [9] that had not foreseen the possible changes that produce new problems [10].

Moreover, in many occasions the plan is considered as the main or single product of the planning process, completely ready for its implementation. Thus, it does not foresee the design and the subsequent establishment of a unit responsible for its implementation [2], capable of making decisions for addressing the unanticipated problems [4, 5] as well as to assure the participation of the indispensable and qualified personnel in the implementation process, instead of the traditional involvement of all staff, reducing thus substantially the costs that the implementation generates $[3,11]$.

Also, there are external factors affecting the execution of a plan such as changes in the political, economic and social environment [5, 6]. Many times, these factors deviate the priorities in the execution of projects and resources allocation [12], which leads to cases in which only 24 percent of institutions, on average, have begun the implementation more than two years after the plan was formulated [13], and of this amount, only 28 percent have achieved their goals in time and in accordance with the budget, 18 percent of the plans have been canceled and the other 54 percent have exceeded their time and budget projections $[3,14]$.

This situation does not improve even if there is a staff responsible for the implementation of the plan, because frequently their capabilities are not sufficient to perform the necessary activities $[5,8]$ due to their inadequate training [4]. Additionally, when these capabilities are sufficient, the personnel frequently lose interest [7] due to a traditional consideration of the implementation as a process less glamorous than the plan formulation. Also, very often there are displays of dislike from the personnel involved in the implementation, resulting in comments that the plan will not work based on their "bad past experiences" [15], due to the mandatory nature of the process, especially when it does not permit to consider their proposals or interests.

All of this causes low level of participation and absences in meetings dedicated to reporting and assessing progress, as well as the lack of collaboration and communication between the organization's departments [5, 11].

Moreover, this situation is aggravated by the absence of formal communication among the personnel responsible for the implementation [16] that results in duplicated efforts [13], with consequent increases in costs and waste of resources [17] which altogether causes achievements and performance to be below the expected level and only 20 percent of the objectives of a plan to be achieved on average [11].

Finally, inadequate management and leadership by managers responsible for the implementation $[4,16]$ and insufficient administrative support of top management [17] cause many well-formulated strategies not to be implemented properly [7].

According to [18], to resolve this kind of manifestations, which in this case affect the process of implementation of strategic plans, it is essential to define and solve the problems that cause them by the conceptualization of the involved systems and the analysis of the relations among them, their subsystems and components.

Therefore, the next chapter is dedicated to the determination of the system responsible for the implementation process, which according to the systems approach [19], in this case means to define the concept of implementation. 


\section{Definition of the concept of implementation}

The conceptualization of implementation as a system was obtained by using the functional decomposition procedure of the system construction method [20] based on the systems approach which permits to consider the implementation as a component of the management system and of the planning subsystem, respectively [21], that is described in the next subchapter (2.1). Consequently, to complete the conceptualization process, the corresponding implementation control and implementation execution subsystems of the implementation system are defined and described in the subsequent Subchapters 2.2 and 2.3; next, the existing information and execution relationships are identified and characterized in Subchapter 2.4.

\subsection{Conceptualization of implementation as a system}

According to [22], the management process could be considered as a system which manages the production system and consists of the following four subsystems: planning, which provides policies, strategies and action programs in the short, medium and long term; decision making, which is responsible for selecting one of the possible courses of action to ensure optimal performance and development of the organization through the achievement of the objectives, strategies and goals; execution, whose responsibility is to transform the decisions in the implemented actions; and information support, which has to provide information about the current and desired state of the organization as well as about its environment (Figure 1). In this case the implementation of the decisions related with the plan is performed through the execution subsystem considered as a component of the management process.

In turn, the planning process, considered as a system [22], consists of the following four subsystems: diagnosis, which determines the problems of the organization as well as its management; prescription, which produces the solution of the problem; instrumentation, which determines the objectives, strategies, policies, programs and/or projects, as well as other components of the plan; and control, which is responsible for implementing the plan and its adaptation to changing environmental conditions (Figure 1). In this case, implementation constitutes a component of the control subsystem of the planning system.

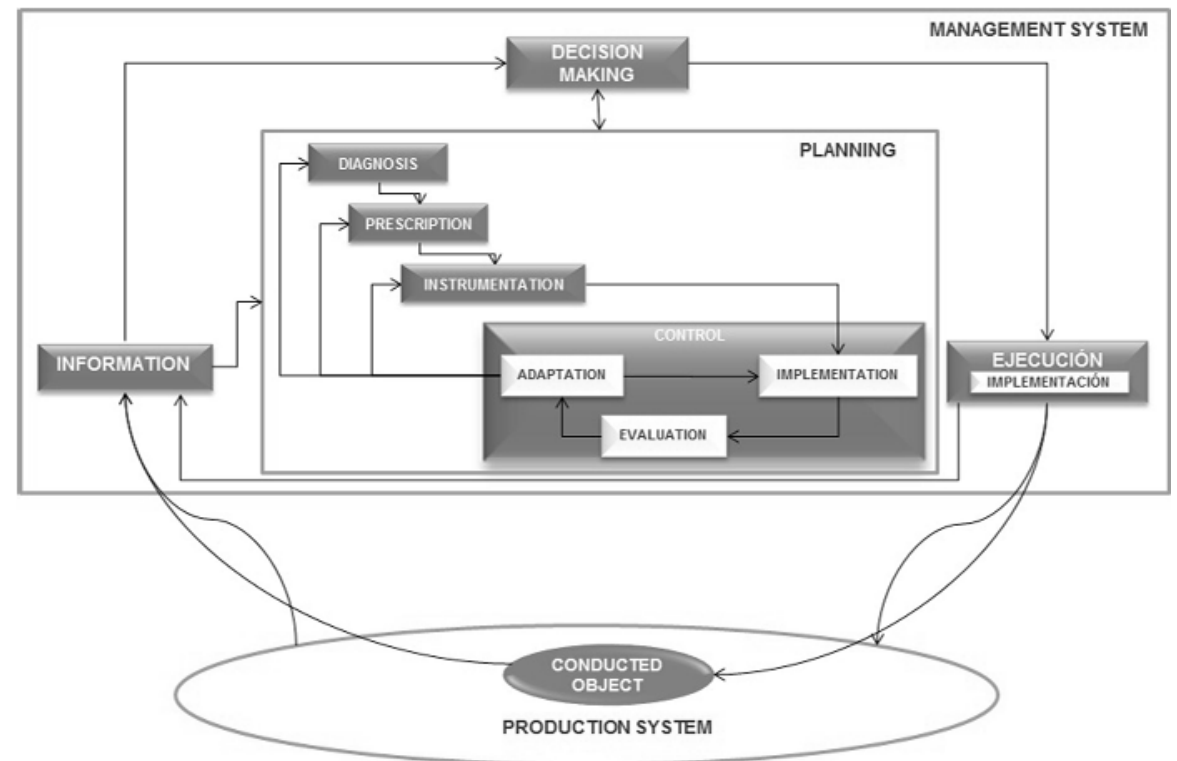

Figure 1. The double role of the implementation in the planning and management processes. 
These considerations permit to conclude that the implementation has two main roles (Table 1):

- One, as a component of the control subsystem of the planning system, the implementation is responsible for the plan execution as well as for the monitoring of the performed activities and their consequences in order to support the consequent evaluation of its efficacy and efficiency necessary to ensure the following updating and adaptation of the plan to the changing state of the organization and its environment.

- Second, as a component of the execution subsystem of the management system, the implementation has the task of turning the decisions into actions in order to ensure their proper and timely execution. It must also assure the fulfillment of the internal and external regulations of the organization.

To assure the fulfillment of these two roles, two types of functions, presented in Table 1, corresponding to the planning and management processes have to be accomplished, respectively.

To complete the definition of implementation system it is important to identify and define two main subsystems that form, according to the cybernetic paradigm [20], any system: the one that governs, manages or controls the other, which is the controlled or conducted one. The first one is named here as the implementation control subsystem and the second one as the implementation execution subsystem.

\begin{tabular}{|l|l|l|}
\hline Type & Implementation Roles & Functions \\
\hline I & In Planning Process & $\begin{array}{l}\text { Execution of the plan } \\
\text { Monitoring of the plan execution } \\
\text { Support to evaluation subprocess }\end{array}$ \\
\hline II & $\begin{array}{l}\text { In Management } \\
\text { Process }\end{array}$ & $\begin{array}{l}\text { Execution of decisions } \\
\text { Generating of information } \\
\text { Vigilance of regulations fulfillment }\end{array}$ \\
\hline
\end{tabular}

Table 1. Implementation functions according to their two types of roles.

2.2 Definition of the implementation control subsystem

The implementation control subsystem (ICSb) controls the implementation execution subsystem
(IESb), constituting both the implementation system (IS) and, in turn, it is directed by the management subsystem (MSb) of the management system (MS), as shown in Figure 2. Therefore, it is essential to distinguish and define the various roles that the ICSb has in each of these systems.

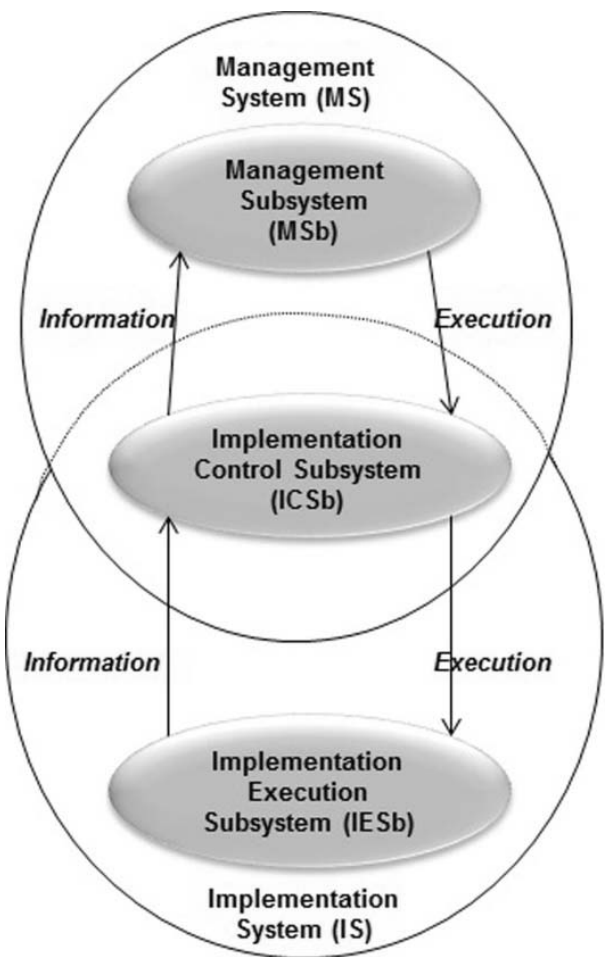

Figure 2. Conceptualization of the implementation system.

To accomplish the first role of the implementation control subsystem (ICSb), as a conducted object of the management subsystem (MSb) in the management system (MS), it has to fulfill the following basic objectives:

- To assure the timely execution of the decisions by the MSb.

- To generate information about the development of execution actions and their results as well as to deliver it to the MSb.

- To watch for the accomplishment of organizational norms and regulations as well as the plan strategies and policies. 
- To organize and perform the functions of planning and implementation of the ICSb activities, according to the organizational objectives.

- To coordinate the relations with other management subsystems of the organization.

At the same time, to accomplish the other role that has the ICSb as part of the implementation system; when it controls the IESb, it must meet the following objectives:

- To execute programs and actions of strategic plans as well as the unforeseen activities which surge due to the needs to attend the changes in the organization and its environment.

- To monitor the implementation of the planning process in each of its phases, providing as well the information for the development and consequent implementation of the corrective actions.

- To support the evaluation sub-process through the identification of indicators for assessing the effectiveness and efficiency of the performed implementation actions according to the obtained results.

- To take advantage of knowledge, experience and skills related with the implementation process of the personnel working in the IESb.

\subsection{Definition of the implementation execution subsystem}

The conceptualization of the implementation execution subsystem (IESb) starts with the definition of its objectives. It is important to take into account that, on one hand, the IESb is a component of the IS, being thus responsible for the execution of activities necessary for the implementation of the strategic plan. On the other hand, it is a subsystem of the production system (PS), in which the main part of the plan has to be implemented.

To accomplish these two roles, the IESb must fulfill the following basic objectives:

- To carry out, timely, the decisions of ICSb.

- To provide the ICSb with the relevant information about the current status of implementation activities.
- To prepare the PS for the implementation of the strategic plan.

- To perform effectively, efficiently and timely the foreseen strategic plan activities, ensuring their realization by the coordination with other systems, subsystems and their components.

- To carry out the legislation and standards established by the organization and to abide its policies.

These objectives are achieved through the IESb functioning, which in turn is assured, as in any system, by the performance of its corresponding internal structure formed by certain functional components. These components, conceptualized by the process of construction by composition [20], are constituted by a set of labor positions (LP), in which each one of them is defined by certain responsibilities with assured attributions and with a sequence of activities, determined by their place in the hierarchy of the organizational structure as well as by the process of implementation of the corresponding strategic plan. Each LP is occupied by one employee responsible to fulfill the corresponding obligations defined usually by the organization internal regulations [23] and the implementation of the strategic plan.

These components formed by the LP and a person that occupies it as well as the hierarchical interrelations between them form the internal structure of the IESb (Figure 3).

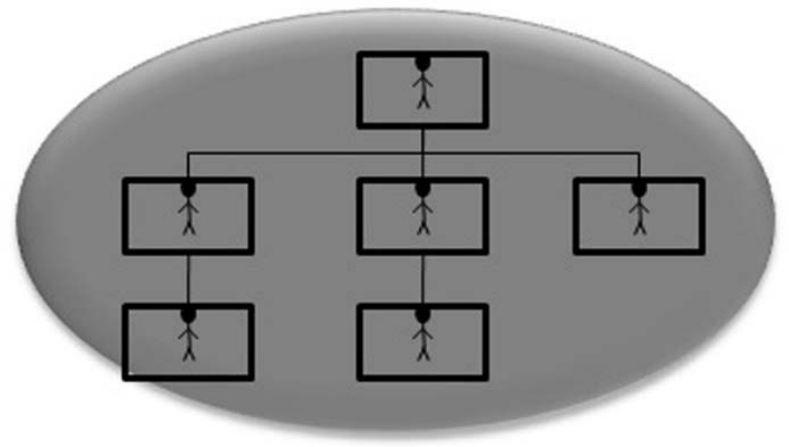

Figure 3. Conceptualization of the internal functional structure of the IESb. 
The next and very important step of the conceptualization process of the IS constitutes the definition of the internal and external information and execution relationships.

\subsection{Definition of the information and execution relationships}

The IS as any system is characterized by its relationship with other systems and their components as well as with the environment; these relations take place among its subsystems and their components. Among these relations, information and execution relationships stand out, which are indispensable to assure the fulfillment of the objectives determined in the previous subchapters.

The information relationship (IR) provides the required information about the state of the system and its environment necessary for the efficient management through decision making, planning and implementation processes. Particularly, in the case of the IR between ICSb and MSb, it permits the ICSb to fulfill one of its objectives ("To generate information about the development of execution actions and their results as well as to deliver it to the MSb"). Besides, the IR provides, in this case, the information required by MSb about the actual state of the IS and its environment as well as about the ICSb activities and their results.

The execution relationship (ER) is used to implement the decisions made. In case of the ER between the MSb and the ICSb, it should fulfill the needs of the MSb to assure the efficient and timely implementation of the strategic plan by:

- Establishing or improving the organizational structure of the IS with the corresponding LP.

- Developing the objectives and policies of the IS as well as determining them in case of necessity.

- Implementing the unforeseen and corrective decisions.

- Approving or correcting the revised IS activities, including the authorization of new actions oriented to improve the implementation process.
In the same manner, the IR and ER between the $I C S b$ and IESb have been also defined. Thus, for example, the IR between them provides the knowledge about the IESb current state in order to permit the ICSb to make the decisions to obtain a better performance of its personnel by changing the current state of the IESb through the ER. Also, the IESb, based on information obtained through the IR, could ensure a healthy and productive work environment in the IESb, solving the disagreements and conflicts when they arise by the ER.

The obtained definitions of both implementation control and implementation execution subsystems as well as of the information and execution relationships complete the conceptualization of the implementation system's functional structure (Figure 4).

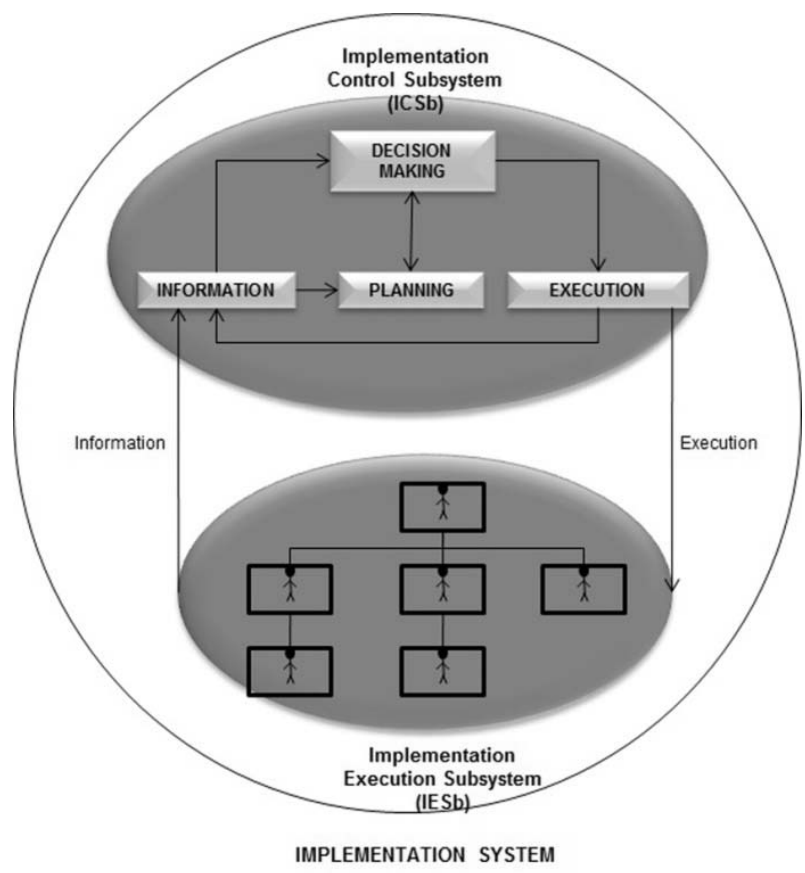

Figure 4. The implementation system's functional structure.

This new vision has permitted to identify the problems, which affect the functioning of the implementation system and particularly damage the implementation process of strategic plans. The obtained results are presented in the next chapter. 


\section{Determination of the implementation problems}

The analysis of the manifestations with their negative consequences, whose effects on the implementation process were described in the Introduction, has permitted, according to the new conceptualization, to identify two kinds of problems that cause them [24]:

- One, named organizational problem (OP), is due to the lack of the adequate organizational structure that is necessary to assure the strategic plan implementation. It is characterized by the absence of some components (units) and/or corresponding specific labor positions (LPS) in the organizational structure as well as by the lack of certain information and execution relationships (IR and ER) between them. As examples, it could be mentioned the lack of:

> Appointment of LPs explicitly responsible for the implementation of the plan,which frequently results in the implicit involvement of the entire personnel of the organization with the consequential substantial increase of the implementation costs [25]

$>$ Explicit determination of formal mechanisms for communication (IR and ER) between the responsible LPs and organization personnel in general, which results in occurrence of arbitrary decisions, not based on precise information and moreover without the consideration of the plan guidelines, as well as with negative consequences due to the inefficient or even incorrect implementation of the decisions made [26].

$>$ The coordination of corresponding activities during the implementation, which leads to inefficient and ineffective results $[4,5]$.

$>$ The collaboration and communication between the different organizational components, that results in difficulties to carry out the plan implementation activities [5, 25].

- Meanwhile, the other one, named functional problem (FP), is caused by the absence of specific functions or their unsatisfactory fulfillment that could occur when the personnel, which occupy the corresponding LPS, do not properly perform the corresponding activities, no matter that the organizational structure is completely adequate. Additionally, sometimes, the implementation activities exceed the functions established for this organizational structure, resulting thus in an ineffective and inefficient execution of the implementation process. The following can be mentioned as examples:

$>$ A lack of adequate management and leadership by the Direction due to the incomplete or erroneous determination of their responsibilities and functions during the implementation process $[4,26]$.

$>$ A lack of sufficient participation of the personnel in the information and assessment meetings of the implementation process [5, 25].

> A lack of operational capacity of the responsible staff, because the implementation activities and specially the corresponding training of the personnel have not been considered in the plan $[5,9]$.

$>$ A lack of pertinent decision making when necessity to attend the unanticipated situations arises [4, 5].

Timely prevention of these problems, as well as adequately solving them when they arise, constitutes a very important task considering that it would permit to assure the appropriate execution of the implementation process. The corresponding methodology developed for this purpose [24] is described in the next chapter.

\section{Methodology for the organization, planning and execution of the implementation process}

As mentioned before, the prevention of both kinds of problems, identified and described in the previous chapter, or their solution provided they arise, permit to assure the correct, timely and efficient execution of the implementation process, constituting thus the main and substantial part of the developed methodology. As can be observed in Figure 5, which shows the sequence of procedures and actions, described in the following subchapters, this methodology is used to verify 
and assure the correct organization and functioning of the implementation process of the strategic plan.

\subsection{Diagnosis of the organizational structure and its operation}

The first methodological procedure, which corresponds to the initial Prevention Phase, aims to diagnose the organizational structure and the state of its operation. This implies the need to obtain, collect and analyze, mainly through the organization manual as well as by surveys and interviews, the information about the organizational structure with its labor positions (LP), their functions and interactions as well as the procedures and activities that have to be performed and are currently being performed.
Of course, due the large amounts of LPs and their interactions, it is indispensable to focus this investigation on the organizational preparedness and abilities to consider only the needs of the task of the strategic plan implementation

That is why it is important to identify the existence of entities in the organizational structure with their LPs that fulfill the role and functions of any of the two main subsystems of the implementation system (IS), namely:

- The implementation control subsystem (ICSb), described in Section 2.2.

- The implementation execution subsystem (IESb), described in Section 2.3.

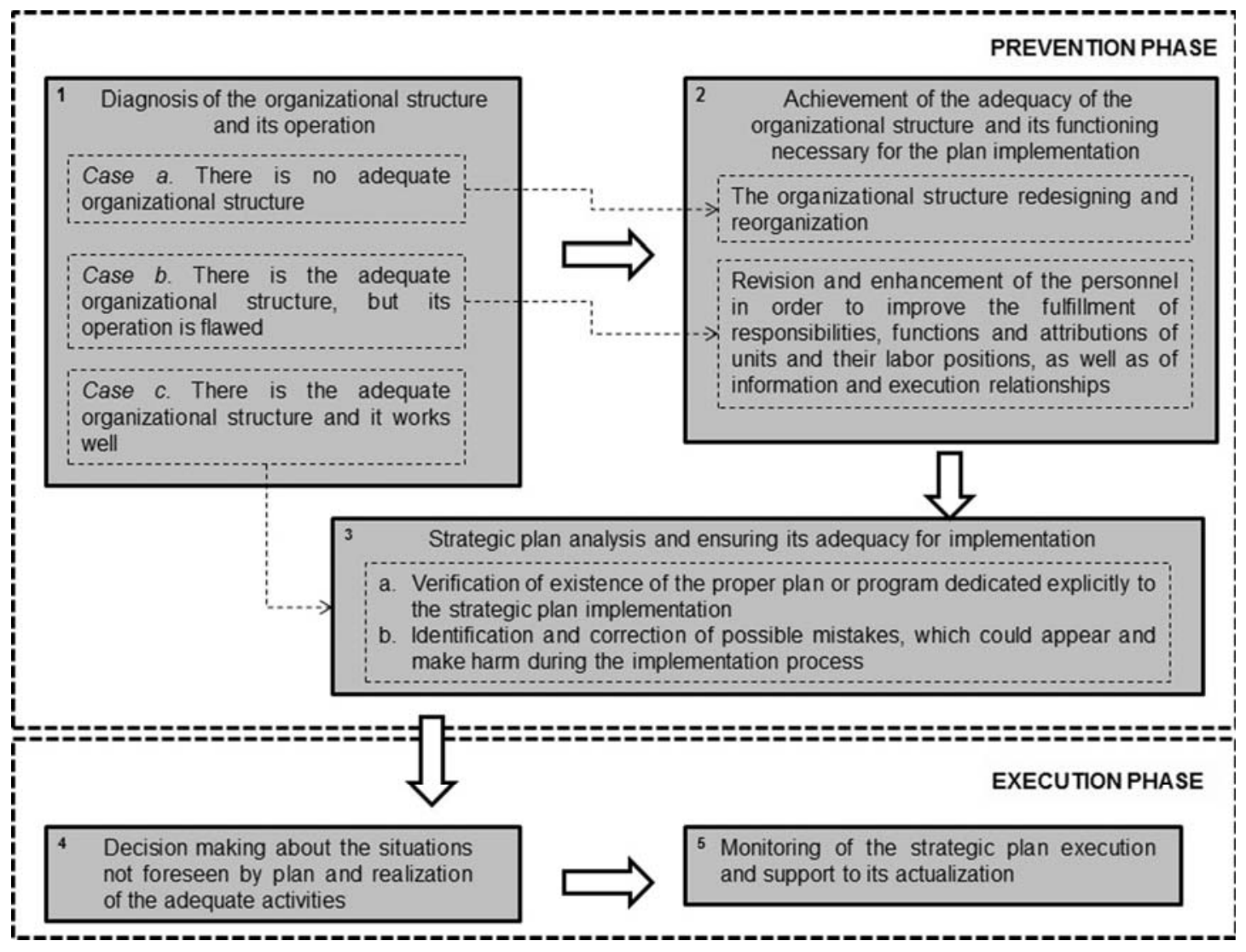

Figure 5. The sequence of the methodological procedures for a strategic plan implementation. 
Even if it occurs, to find out and confirm that there are no problems with the organizational structure, it is indispensable to verify as well its correct functioning and operation.

In the case when the diagnosis results are completely positive, the procedure dedicated to the strategic plan analysis, described in Subchapter 4.3 (Figure 5), can be performed.

In the contrary case, when any discrepancies in the organizational structure and/or any possible faults in its operation are detected that could affect the future implementation of the strategic plan, the procedure has to be carried out, described in the next Subchapter 4.2, dedicated to the improvement of the organizational structure and its functioning to make them comply with the necessities of the implementation process.

\subsection{Achievement of adequacy and functioning of} the organizational structure necessaries for the plan implementation

The decisive factor to ensure an adequate implementation process is to have a special entity, responsible for coordinating and directing the process for the execution of the strategic plan, positioned on the highest level of the organizational structure and preferably headed by the organization director who is in charge of making the important decisions.

Moreover, in case of occurrence of situations not contemplated by the plan and in order to ensure the accomplishment of the objectives planed, this entity, named as the Consultative Council or the Operating Council, has to determine and make decisions about the unforeseen activities and to verify their executions. Besides, it must make the appropriate decisions to update the strategic plan in advance, according to the assessment of the effectiveness and efficiency of the implementation process done by another special entity named as the Implementation Committee (to be described later).

The main function of the Consultative Council is to make the corresponding suggestions related with the development and execution of the strategic plan as well as to propose them to the Direction for their approval. Other alternative is to make it part of a mightier Operating Council who can make the necessary decisions (Figure 6)

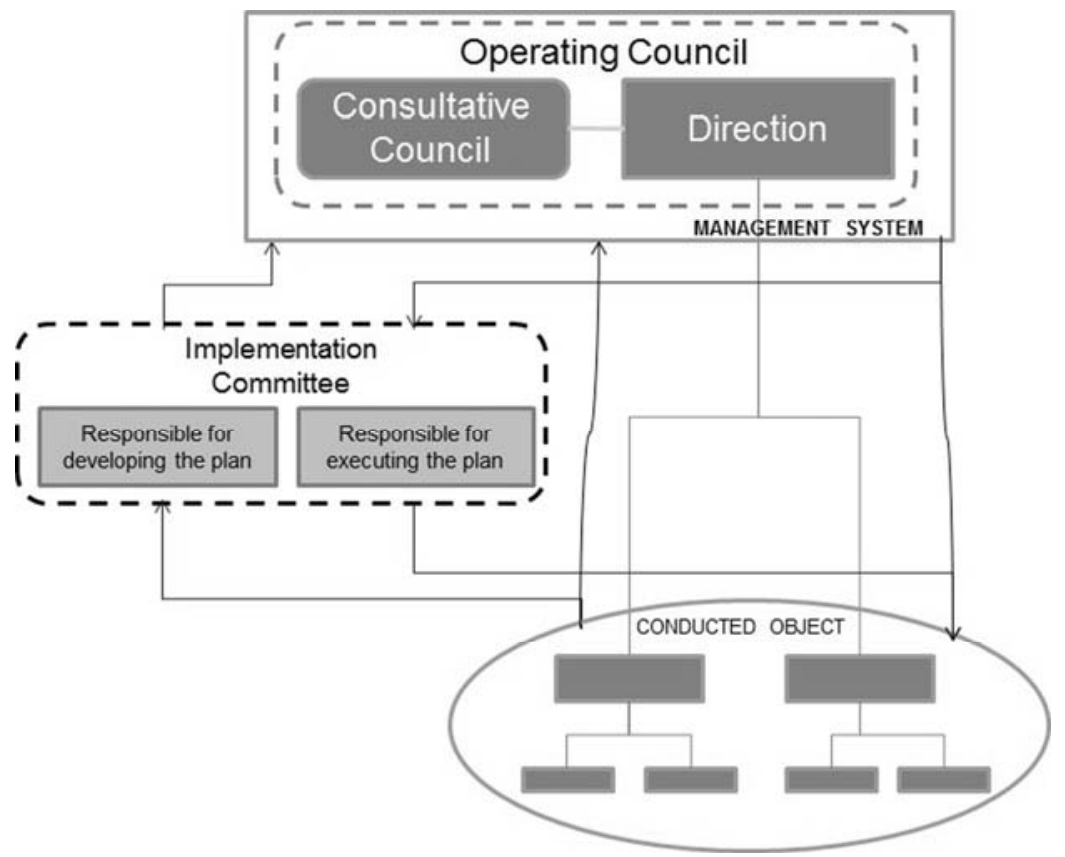

Figure 6. Special components of the organizational structure recommended for the strategic plan implementation. 
To have the necessary information and professional support, any of these Councils has to establish and supervise an Implementation Committee (Figure 6) composed by the managers of the organization entities, who are in charge of the plan elaboration, its revision and execution. Thus, these councils can charge the Implementation Committee with the application of Procedure 2 (Figure 5) in order to assure the adequacy and functioning of the organizational structure, which is necessary for the plan implementation, through the redesign and/or reorganization of the organizational structure and, moreover, through the revision and enhancement of the personnel in order to improve the fulfillment of responsibilities, functions and attributions of units and their labor positions, as well as of information and execution relationships

Furthermore, this committee has to be responsible for the revision of the plan and the preparation of the necessary conditions for its implementation such as its preliminary dissemination and promotion among the personnel of the organization, by emphasizing the benefits that it would provide them; also, is responsible for their adequate preparation and training to assure the required abilities.

The next procedure, described in the subsequent subchapter, permits the Implementation Committee to analyze the feasibility of the successful implementation of the plan and to develop, if necessary, the required changes, as well as to deliver the corresponding propositions to the Consultative Council or Operating Council for their endorsement to assure the timely and efficient execution of the strategic plan.

\subsection{Analyzing the strategic plan and ensuring its adequacy of implementation}

The analysis of the strategic plan starts with the execution of Subprocedure 3a (Figure 5) which permits to verify the existence of the special implementation plan or program and the viability of its execution. Besides, it is important to verify the existence of basic components of the strategic plan and the consistency among them, such as vision, mission, objectives, performance goals, key assumptions, policies, strategies, planning horizon, plans and operational programs, duties of the responsible staff, coordination with third parties, budget assignments, and so on.

The next step, according to Sub-procedure 3b, consists in elaboration of the possible scenarios of the implementation process to correctly identify in advance probable errors in the strategic plan and, especially, those related to its implementation plan, which might arise and cause damage during the implementation process. It is advisable to simulate this process, through the use of information technology means, to verify its feasibility.

\subsection{Making the decisions and performing unforeseen activities in the plan}

In spite of the achievement using Procedure 3 of a successful analysis of the strategic plan and its feasibility for the implementation, it is important for the organization through its corresponding body, which can be the recommended Implementation Committee, to be prepared to face and attend some unforeseen situations by the strategic plan and, moreover, by its implementation plan.

The causes of occurrence of these situations, unexpected and sometimes unforeseeable, can be of different kinds, including unanticipated changes in the environment and/or the proper organization as well as possible errors in the assumptions on which the planning process has been based. Of course, the failures and mistakes of the personnel as well as the usual and unpleasant budget adjustments should not be forgotten. Therefore, during the Execution Phase (Figure 6), the Implementation Committee should provide, timely, the Consultative Council or even the Operating Council with relevant information for their optimal decision-making about the corresponding actions and also for controlling their execution by applying Procedure 4.

4.5 Monitoring of the execution and updating of the strategic plan

The applying of the last, but not least important, methodological procedure takes place during the Execution Stage and aims to monitor the execution process in order to assess the effectiveness and efficiency of the performed activities and also to evaluate the obtained results and their real costs/benefits. Consequently, this permits to 
determine the need for improving the possible errors made before during the plan elaboration. Also, it serves for updating the plan to meet the changes in the organization and its environment.

Thus, the application of Procedure 5 implies the implementation of the following steps (subprocedures) in order to

- Perform the programs and activities according to the implementation plan.

- Watch over the fulfillment of responsibilities and the performance of functions by the organizational structure staff, as well as solicit the Consultative Council or Operating Council to make decisions about changes related to personnel appointment in labor positions to ensure better performance when necessary.

- Promote a healthy and productive work environment by resolving, when necessary, the arising disagreements and conflicts.

- Monitor the implementation process, ensuring the compliance of activities planned according to the resources and verifying, at the same time, that policies and regulations of the organization are met.

- Support the evaluation of the effectiveness and efficiency of activities and obtained results.

- Revise the plan according to evaluation results and develop the relevant suggestions of its adjustment.

- Report, timely, to the Consultative Council or Operating Council the evaluation results as well as the suggestions of the plan adjustment for their approval.

Obviously, the Implementation Committee must establish, in advance, the relevant mechanisms for performing and coordinating the execution, monitoring and evaluation of the strategic plan as well as the establishment, maintenance and operation of the information and execution relationships, especially with the Consultative Council or Operating Council to obtain the approval of the suggestions and to assure the fulfillment of the decisions.

\section{Validation of the implementation methodology}

The developed methodology has been validated by showing how the consequent application of each of its five procedures can reduce and, where appropriate, prevent the occurrence of the manifestations and their negative consequences known from the literature and described in the introduction, resolving thus the corresponding problems of the plan implementation.

It has been demonstrated that

- The execution of Procedure 1, diagnosis of the organizational structure with its operation, and Procedure 2, achievement of the adequacy of the organizational structure and its functioning for the plan implementation, could prevent, attend and resolve the aforementioned situations when:

$>$ the strategic plan was considered as the main and only product of the planning process without any considerations of the need to design and count with the special entity of the organizational structure responsible for its implementation as well as for making the decisions to attend the unanticipated problems and to assign the corresponding personnel and not to involve everyone in the organization, reducing thus the costs it generates.

$>$ the capacity of the responsible staff was insufficient to perform the activities involved in the implementation process.

$>$ there was a lack of formal communication between the implementation personnel that resulted in the omission of the plan guidelines.

$>$ there were not many properly implemented strategies, though well-formulated, due to insufficient management and lack of leadership as well as inadequate administrative support of top management.

- The next compliance of Procedure 3, analysis of the strategic plan and ensuring its adequacy of implementation, could resolve the following situations when: 
$>$ The implementation exceeded the time anticipated by the strategic plan because it did not contain specific activities for their implementation or, even if it contained them, there was not sufficient coordination of their execution to achieve efficiently the planned results.

$>$ There were serious difficulties during the plan implementation, in spite of the existence of the unit responsible for the implementation because of the lack of capacity of the personnel whose training was not foreseen by the plan.

- Moreover, if Procedure 4, decision-making and performing activities not foreseen by the plan, was accomplished, it was possible to resolve the situation when:

$>$ the implementation had taken longer than expected because of the incomplete program of activities that the strategic plan contained as well as because of the inefficiency of these activities.

> running of the strategic plan, which was considered as a political instrument, constituted a post-process with other strategic requirements and resources that complicated substantially its implementation.

$>$ unanticipated problems arose that caused setbacks in the decision-making process aimed at resolving them or the decision was erroneous as to cause new problems.

- Finally, the accomplishment of Procedure 5, monitoring of the execution and updating of the strategic plan, permits to attend the following situations when:

$>$ having to make adjustments in the plan during its implementation, serious inconveniences and difficulties arise because of insufficient flexibility of the plan, which, besides, did not contain any necessary indications.

$>$ certain external factors occurred, such as changes in the political, economic and social environment, which affected the plan implementation deviating the priorities in the projects execution and resources allocation.

\section{Conclusions}

It has been shown that there is a great number and variety of harmful situations and serious consequences that may appear during the implementation of strategic plans. Unfortunately, the resolutions suggested and described in the literature are frequently limited and partial. Moreover, these propositions are often redundant, not compatible or, in some cases, contradictory. Usually, this is due to the use of different terms or, even in the case when they use the same terms, those terms correspond to different concepts as far as distinct authors use diverse conceptual frameworks. Therefore, the first resolved task was the development of a general definition of the concept of implementation by employing the systems approach and the cybernetic paradigm.

This definition, as well as the analysis of the situations and negative consequences that affect the implementation process, permitted to identify two types of problems that cause them:

- Organizational problems: which are due to the absence of some entities and certain labor positions in the organizational structure as well as to the lack of the corresponding interrelationships among them.

- Functional problems: which arise when, in spite of the existence of responsible entities with the corresponding labor positions for the execution of the implementation process, they do not perform properly the assigned functions and activities.

To provide the measures that permit to avoid either type of problems, or to resolve them, assuring thus the efficient implementation of the strategic plan, the corresponding methodology was developed that consists of the following five procedures:

1. Diagnosis of the organizational structure and its operation.

2. Achievement of the adequacy of the organizational structure and its functioning.

3. Analysis of the strategic plan and ensuring its adequacy of implementation. 
4. Making the decisions and performing activities unforeseen by the plan.

5. Monitoring of the execution and updating of the strategic plan.

The methodology was validated by proving that its application to the aforementioned problems, which usually affect the implementation process, prevent and resolve them.

Moreover, the sociopolitical importance Procedure 5 is revealed as far as it emphasizes the continuity of the planning process, which should not be restricted only by the production of the plan, but has to be considered as a continuous and balanced process of development, implementation and improvement, through the satisfaction of the conditions that each of the procedures pursue.

\section{References}

[1] Mintzberg, H. (1994), "The Fall and Rise of Strategic Planning"; Harvard Business Review; Jun-Feb 1994, pp. 107-114.

[2] Ackoff, R.L. (1973), "Science in the Systems Age: Beyond IE, OR, and MS", Operations Research, Vol. 21, No. 3, pp. 661-671.

[3] Shufeldt, L. (2007), "Importance of project management", The AlIM Guide to ECM Purchasing, AlIM International, pp. 71-74.

[4] Schaap, J. (2006), "Toward strategy implementation success: an empirical study of the role of senior -lever leaders in the Nevada gaming industry," UNLV Gaming Research \& Review Journal, Vol. 10, Issue 2, pp. 13-37.

[5] O'Regan, N. and A. Ghobadian (2007), "Formal strategic planning: annual raindance or wheel of success?," Strategic Change, No. 16, Jan-Apr 2007, pp. 11-22.

[6] Miller, S., Wilson, D., and D. Hickson (2004), "Beyond planning strategies for successfully implementing strategic decisions," Long Range Planning, No. 3, Vol. 37, pp. 201-208.

[7] Goleen, M., Anderson, D., Toombs, L. and J. Humphreys (2007), "Strategic implementation as a core competency". Journal of Management Research, Vol. 7 No. 1, Apr. 2007, pp. 3-17.

[8] Zuckerman, A. (2006), "Execute a successful strategic plan", Healthcare Executive, Vol. 21, No. 2, Mar-Apr, 2006, pp. 76.

[9] King, W.R. (1982), "Using strategic issue analysis", Long Range Planning, Vol. 15, No. 4, Aug. 1982, pp. 45-49.

[10] Checkland, P. (1981), "Systems thinking, systems practice", Ed. John Wiley \& Sons.

[11] Lederer, A. and V. Sethi (1988), "The implementation of strategic information systems planning methodologies", MIS Quarterly, Vol. 12, No. 3, pp. 445-461.

[12] Hartono, E., Lederer, A. L., Sethi, V. and Y. Zhuang (2003), "Key Predictors of the Implementation of Strategic Information Systems Plans", ACM SIGMIS Database, Vol. 34, No. 3, pp. 41-53.

[13] Gottschalk, P. (1999), "Strategic information systems planning: the IT strategy implementation matrix", European Journal of Information Systems, Vol. 8, No. 2, June 1999, pp. 107-118. 
[14] Brache, A. P. and S. Bodley-Scott (2005), "Implementation", Ed. Mc Graw Hill, pp. 195.

[15] Nutt, P. (1992), "Managing planned change", Ed. Mc Millan Publishing Company, pp. 558.

[16] Ruch, B. (2004), "Tools for optimizing your plan", Camping Magazine, American Camping Association, Vol. 77, No. 6, Nov-Dic 2004, pp. 1-6.

[17] Serge, P., (2005), "Diversity models in organizations", International Journal of the Diversity, Vol. 5, No. 4, 2005/2006

[18] Gelman O. (2010), "El papel del marco conceptual y la base metodológica en la investigación interdisciplinaria", Memorias del Simposio "La investigación interdisciplinaria: retos y perspectivas en en México", Eds. Ana Maria Hernández Anguiano, Fernando Carlos Gómez Merino y Carlos Miguel Becerril Pérez, El Colegio de Postgraduados (COLPOS), Campus Córdoba, 20-30pp.

[19] Gelman O. \& García J.I. (1989), "Formación y axiomatización del concepto de sistema general". Boletín de IMPOS, Instituto Mexicano de Planeación y Operación de Sistemas, Año XIX, No. 92, 81 pp.

[20] Gelman, O. (1996), Desastres y protección civil, Fundamentos de Investigación Interdisciplinaria, Ed. UNAM, México, pp. 133.

[21] Rojas-Arce J., Gelman O., y Suárez-Rocha J. (2008) "Hacia un esquema conceptual de implementación de planes estratégicos en organizaciones". En "Pensamiento y Práctica de Sistemas en el complejo ambiente global y latinoamericano", Memoria de la Tercera Reunión

Regional de ALAS, 6 al 8 de noviembre de 2008, Ciudad de México, en CD, 10 pp.

[22] Gelman, O. y G. Negroe (1982), Planeación como un proceso de conducción." Revista de la Academia Nacional de Ingeniería, México, Vol. 1, No. 4, pp. 253-270.

[23] Rigaud-Tellez N., Gelman O., and Suárez-Rocha J. (2008). "Towards of Conceptual Framework for the Interdisciplinary Human Resources Management Research". In Complex Social Systems, Interdisciplinarity and Work Futures, Proceedings of the 8th International Conference on Sociocybernetics in Mexico City, ISBN 978-970-32-5231, Centro de Investigaciones Interdisciplinarias en Ciencias y Humanidades, Universidad Nacional Autónoma de
México, CEIICH-UNAM, Ciudad de México, México, June 23 to 27, 2008. pp. 1-20

[24] Rojas-Arce, J. (2011), "La Metodología para la Organización y Realización del Proceso de Implementación de Planes Estratégicos en Instituciones y Empresas", Tesis de Doctorado, Directores de Tesis: Dr. Javier Suárez Rocha y Dr. Ovsei Gelman Muravchik, Programa de Estudios de Posgrado en Ingeniería, UNAM, México.

[25] López, A. \& Domingo R. (2005), "El problema de implantar mejoras en las empresas", IDE-CESEM Instituto de Directivos de Empresa, España, revised 25 January 2012: http://www.acedis.com/Problematica-enla-Implantacion-de-Mejoras-en-las-Empresas-

4_5_158.html

[26] Ramió-Matas, C. (2001), "Los problemas de la implantación de la nueva gestión pública en las administraciones públicas latinas: modelo de Estado y cultura institucional", Revista del CLAD Reforma y Democracia, Caracas, No. 21, Oct. 2001, pp. 24. 